\title{
EL SEISCIENTOS, UN SÍMBOLO SOCIAL DE LA ESPAÑA DEL DESARROLLISMO
}

\author{
THE SEAT 600, A SOCIAL SYMBOL \\ OF SPAIN'S DEVELOPMENTALISM
}

\author{
Isabel Martín-Sánchez* \\ Universidad Complutense de Madrid, España
}

RESUMEN: Uno de los símbolos más emblemáticos de la segunda mitad del siglo xx en España es el Seiscientos. Este vehículo, que recibió múltiples acepciones populares, como «pelotilla», «Seílla», «garbancito», forma parte de la memoria colectiva y marcó a varias generaciones, debido, no solo a su alta demanda y difusión, sino a la amplitud del periodo de producción, que abarcó dieciséis años, desde los inicios de su fabricación, en mayo de 1957, hasta agosto de 1973, en los que se produjeron 794.406 unidades. $^{1}$

Pero el Seiscientos fue también el símbolo del periodo de «desarrollismo» de los años sesenta, en los que España experimentó una profunda transformación económica, social y cultural. Este utilitario fue representativo de un mayor status social: el de la clase media surgida de ese crecimiento económico.

PALABRAS CLAVE: Seiscientos; SEAT 600; desarrollismo; franquismo; historia social y económica

ABSTRACT: One of the most emblematic symbols of the second half of the $20^{\text {th }}$ century in Spain is the SEAT 600. This vehicle, which received multiple popular names, such as pelotilla (small ball), garbancito (small chickpea) and Seilla, is part of the Spanish collective memory and influenced several generations. This is caused not only by its high demand and outreach, but also due to its long time of production comprising 16 years (from May 1957 up until August 1973), during the course of which a total of 794,406 units were manufactured.

Besides, the SEAT 600 was a symbol of the 'developmentalism' of the 1960s, in which Spain underwent a deep economic, social and cultural transformation. This vehicle stood for a higher social status: that of the middle class which had emerged as a result of the economic growth.

KEYWORDS: SEAT 600; Developmentalism; Franco Regime; Social and Economic History

1 http://www.seat.es/somos-seat/seat-600.html.Última consulta realizada el 22 de agosto de 2017.

* Correspondencia a: Isabel Martín Sánchez. Dpto. de Periodismo y Comunicación Global. Facultad de Ciencias de la Información. Universidad Complutense de Madrid. Avda. Complutense, s/n, 28040 Madrid. - imartin@ucm.es - https:// orcid.org/0000-0002-6400-8920

Cómo citar: Martín-Sánchez, Isabel (2019). "El Seiscientos, un símbolo social de la España del desarrollismo»; Historia Contemporánea, 61, 935-969. (https://doi.org/10.1387/hc.19535).

Recibido: 2 abril, 2018; aceptado: 26 septiembre, 2018.

ISSN 1130-2402 - eISSN 2340-0277 / (C) 2019 UPV/EHU 
«...lo que más me duele, Mario, es que por unos cochinos miles de pesetas, me quitases el mayor gusto de mi vida, que yo no te digo un Mercedes, que de sobra sé que no estamos para eso, con tanto gasto, pero qué menos que un Seiscientos, Mario, si un Seiscientos lo tienen hoy hasta las porteras, pero si les llaman ombligos, cariño, ¿no lo sabías?, porque dicen que lo tiene todo el mundo»

Miguel Delibes: Cinco horas con Mario

\section{Introducción}

Dentro de la historia automovilística de España, el Seiscientos es uno de los vehículos que más atención ha recibido. Es precisamente su simbolismo lo que ha atraído el interés de numerosos autores como Cassany y López, Gimeno, Solé y Eslava, quienes le han dedicado varias monografías desde diferentes perspectivas. Por su parte, la empresa SEAT ha sido también objeto de diversos estudios, desde el publicado por Miguélez, ya en 1977, hasta los más recientes de Solé, Roca, Tappi, Balfour o Sanz, entre otros. Especialmente interesantes resultan las investigaciones de San Román y de Catalán, que muestran los entresijos de los orígenes de SEAT, las negociaciones con Fiat y el empeño del INI, y de Suances, en particular, por hacerse con el control «nacional» de la producción automovilística a través de la propiedad estatal de SEAT.

Este trabajo se centra, fundamentalmente, en el Seiscientos como símbolo de los cambios que se produjeron en España en los años sesenta, de índole económica y social, que no política: la dictadura, pese al maquillaje legal de leyes como la Orgánica, de 1966 y su referéndum, y la de Prensa, ese mismo año, junto al establecimiento de los gobiernos de los «tecnócratas», a finales de los cincuenta, no modificaron el carácter dictatorial del sistema político. Incluso, el régimen se tornó más represivo en sus últimos años, ante el creciente panorama de conflictividad social y sindical. Por otro lado, el desarrollo económico no estuvo exento de contradicciones: pese al crecimiento de los sectores industrial y terciario, la creación de empleo fue insuficiente para absorber la mano de obra procedente, esencialmente, del ámbito rural. El desarrollo económico tampoco alcanzó por igual a todas las regiones y capas sociales. Miles de trabajadores se vieron abocados a la emigración económica hacia otros países, con un alto coste social. El crecimiento económico tam- 
bién estuvo sujeto a fluctuaciones. Los primeros atisbos de crisis, antes del colapso de 1973, ya se produjeron en 1968, cuando la difícil situación de Estados Unidos, embarcados en un programa social ambicioso y una costosa guerra en Vietnam, obligaron a la devaluación del dólar y a la revisión del sistema internacional de cambios, basado en la paridad de las divisas frente al dólar, como divisa de reserva convertible en oro. ${ }^{2}$ Panorama que supo retratar Vázquez Montalbán usando un símil comprensible para los españoles de la época: «La civilización automovilística española es la que mejor nos puede prestar su lenguaje para comprender esta alternante situación de la riqueza nacional - escribía-. Como buen conductor del seiscientos, el español medio sabe que en el arte de conducir hay que acelerar de pronto y frenar en el momento menos esperado». ${ }^{3}$

Pese a ello, la década de los sesenta fue una etapa de gran desarrollo económico, sobre todo, en Estados Unidos y Europa occidental, donde se experimentó un aumento del bienestar social. No hay que desdeñar, sin embargo, el registrado en Europa oriental, si bien, se basó más en el fomento de la industria pesada y la tecnología que en los bienes de consumo. Enmarcada en el bloque capitalista, aunque sería más apropiado decir «anticomunista», España vivió el suyo propio, que contribuyó a una elevación del nivel de vida. Sin embargo, aunque este periodo ha trascendido con la denominación de «desarrollismo», España no dejaba de ser un país en vías de desarrollo.

En ese contexto, el Seiscientos fue un utilitario tan modesto, en términos tecnológicos, como el despegue económico del país, pero también supuso el inicio de una sociedad de consumo, en un marco general en el que se operó una transformación - o más bien, evolución - a nivel social y económico. Aquí reside el otro objetivo de este trabajo: mostrar qué supuso la popularización del Seiscientos, sobre todo, con la aparición a finales de los sesenta y comienzos de los setenta de un mercado, no ya de segunda, sino de tercera y aún, de cuarta mano, que permitió que este vehículo estuviese al alcance de sectores con menos recursos. El Seiscientos fue un elemento más, no el único, que simbolizó la modernización social de España, a la que contribuyó no solo la aparición de nuevos bienes de consumo, sino también un clima internacional de profundos cam-

${ }^{2}$ Hobsbawm, 2006, p. 245.

3 Vázquez, 2003, p. 158. 
bios sociales y culturales a los que España no fue ajena. Pero quizá uno de los aspectos más significativos fue el surgimiento de un clima de conflictividad sindical que, pese a los intentos del régimen de atajarlo por la vía represiva, forzó a iniciar un juego de negociación para contener las demandas. Esto supuso la puesta en marcha de nuevas formas de pacto inexistentes décadas atrás, pero también la reivindicación de la libertad para organizarse, ${ }^{4}$ que serían un puntal para el proceso posterior, tras la muerte de Franco.

El primer apartado de este trabajo está dedicado al origen del Seiscientos y aspectos como su demanda, precio y evolución técnica. El segundo ofrece una panorámica del contexto del país, a nivel económico y social y los cambios propiciados por la expansión del vehículo, en general, y del Seiscientos, en particular.

El último apartado recoge la conflictividad laboral en SEAT. A nivel simbólico, resulta interesante la representatividad de la lucha sindical en una de las empresas modélicas del franquismo, lo que la convirtió en uno de los principales objetivos para los sindicatos clandestinos.

Para la elaboración de este trabajo, además de la bibliografía relacionada con el tema, se ha manejado prensa de la época por varios motivos. En primer lugar, para analizar las estrategias publicitarias utilizadas para la promoción del Seiscientos y la evolución de los sectores sociales de consumo. En segundo, porque la prensa es, indudablemente, un registro de la actualidad, en la que se reflejaron los cambios que se estaban operando en el país. Por otro lado, la prensa actuó como pulso de esa sociedad. Frente a la complacencia de la Prensa de Movimiento, portavoz de la propaganda oficial, no faltó la visión crítica de otras publicaciones que se sustrajeron al clima de triunfalismo dominante y pusieron de manifiesto las contradicciones sociales $-\mathrm{y}$ aún políticas - del sistema. Es el caso de revistas como Triunfo y Destino o del diario Madrid, cuyas líneas editoriales evolucionaron en esa década hacia posturas inconformistas. Por último, el recurso a la prensa ha resultado especialmente útil para conocer también la cultura popular que surgió en torno al Seiscientos, a través de las referencias publicadas en la misma y la aparición de términos como seatón, que formaron parte del acervo cultural del momento.

${ }^{4}$ Santos, en Alted, A. y Aubert, P., 1995, p. 34. 


\section{Un coche para un pueblo}

El inicio de la fabricación del SEAT 600 coincidió con el fin de la autarquía y el impulso de una nueva política económica que promovería cambios significativos. Las medidas aplicadas a partir del Plan de Estabilización de 1959 e implementadas en los Planes de Desarrollo (19641975) tuvieron como objetivo, no solo resolver la difícil situación económica del país, acuciado por un alto déficit comercial y un incremento de la deuda pública y la inflación, sino también incorporar a España a la esfera de países occidentales, ante las oportunidades que ofrecía el panorama de la Guerra Fría. La eliminación de la autarquía vino precedida de una salida del aislamiento al que España había sido confinada tras la Segunda Guerra Mundial por su colaboración con las potencias del Eje. En 1953, la firma de los conocidos como Pactos de Madrid con Estados Unidos, por el que el país norteamericano establecía bases militares en territorio español a cambio de ayuda económica y el fomento del intercambio comercial, abriría las puertas al régimen franquista hacia otros organismos internacionales. Ese mismo año, España era aceptada en la UNESCO y dos años más tarde, en 1955, fue admitida en la ONU. En 1958 se integraba en el Fondo Monetario Internacional, que aceptaría, poco después, los planes económicos impulsados por los llamados «tecnócratas», orientados a dinamizar la economía española mediante una progresiva disminución de la intervención estatal y la intensificación de las relaciones exteriores para fomentar la liberalización de las importaciones y transacciones y atraer la inversión de capital extranjero. ${ }^{5}$ La ayuda se materializó también en un asesoramiento técnico para promover la industrialización y la formación empresarial que provocó una hibridación entre las concepciones económicas empresariales norteamericanas y las españolas y que cristalizó en lo que Fuentes Quintana denominó como «modelo castizo». ${ }^{6}$

El resultado de las medidas económicas fue un incremento significativo de la renta nacional. ${ }^{7} \mathrm{La}$ industria fue el sector con un mayor crecimiento, con una tasa media del 9\% entre 1960 y 1974, lo que impulsó el desarrollo de otros sectores vinculados a la misma, como el metálico, el

5 Tamames, 2005, p. 23.

${ }^{6}$ Fuentes, 1995, pp. 255-332. Sobre las relaciones empresariales con Estados Unidos durante esta etapa, véase Puig y Álvaro, 2002, pp. 8-29.

$7 \mathrm{Su}$ valor se triplicó en diez años desde los 532,7 miles de millones de pesetas en 1960 hasta los 1907,5 miles de millones, en 1970. Cfr. Fernández, 2005, p. 62. 
químico y el energético. Durante este periodo, el empleo en el sector primario se redujo casi a la mitad (del 40 al 23\%), en beneficio de los sectores secundario y terciario. ${ }^{8}$ El éxodo desde el ámbito rural al urbano provocó un excedente de mano de obra que fue parcialmente absorbido por los sectores en alza, y que buscó otras salidas en la emigración a otros países, especialmente europeos.

Uno de los focos de atención para el régimen franquista fue la industria del automóvil. En el momento de la creación de la Sociedad Española de Automóviles Turísticos (SEAT), en 1950, se establecían como objetivos fundamentales el fomento de la fabricación de automóviles de turismo como motor de industrialización, la creación de puestos de trabajo y la mejora de las condiciones de vida de los trabajadores, al facilitar la compra de un coche popular, ${ }^{9}$ objetivos que parecían centrarse más en un interés social que económico, propios de la retórica propagandística del franquismo. No hay que olvidar que, en el momento de su fundación, el INI disponía del $51 \%$ de las acciones de la nueva empresa, por lo que la propiedad era mayoritariamente estatal. ${ }^{10}$

El objetivo de crear un coche «popular» con fines propagandísticos ya surgió durante el régimen fascista italiano, a través de la casa italiana Fiat, que lanzaría el modelo 500 Topolino en 1936, y de Hitler, impulsor del «Escarabajo» Volkswagen, que no llegaría a producirse, debido al estallido de la guerra mundial, por lo que su comercialización no se realizaría hasta los años cincuenta. Por su parte, en 1948, la casa francesa Citroën lanzaba el $2 \mathrm{CV}$, un vehículo a bajo precio. Sin embargo, el pionero en la idea de producir un coche dirigido a todos los sectores sociales fue el empresario norteamericano Henry Ford quien, en 1908, creaba el modelo Ford $\mathrm{T}$, un coche de manejo sencillo, robusto y al alcance de las clases

8 Véase Martín y Martínez, en Towson (ed.), p. 5. Sobre la política agraria, véase Gómez, 2004, pp. 65-86.

${ }^{9}$ Solé, 2001, p. 11.

${ }^{10}$ La constitución de SEAT fue el resultado de un largo proceso de negociación durante diez años, a partir del acuerdo original impulsado por el Banco Urquijo y Fiat para crear la Sociedad Ibérica de Automóviles de Turismo (SIAT) en 1940 y cuyo objetivo era el de producir vehículos de bajo consumo y precio. Las diferencias entre Suances, como presidente del INI, y de Carceller, como Ministro de Industria, provocaron el fracaso de este primer proyecto, que no se desbloquearía hasta el nombramiento del primero como Ministro de Industria en 1945, mientras conservaba la Presidencia del INI. Suances forzó la negociación con Fiat para que el INI fuese el accionista mayoritario. Sobre este aspecto, véase San Román, 1995. 
medias. A partir de 1912, Ford aplicó a su producción el sistema taylorista consistente en la cadena de montaje. El resultado fue la reducción del índice número de horas/trabajador y la considerable disminución del precio del vehículo. Este sistema se implantó también a otros sectores proveedores de la industria del automóvil, lo que abarató mucho más su precio. ${ }^{11}$ El sistema no pasó desapercibido para los fabricantes europeos, como André Citroën, Louis Renault o Giovanni Agnelli, presidente de Fiat, quienes desarrollarían modelos similares siguiendo la misma línea.

El proceso de producción en cadena supuso el paso de la producción artesanal a otra industrial, en la que la mecanización del trabajo, criticada por Charles Chaplin en Tiempos modernos (1936), fue compensada con una reducción del precio del producto, pero también por un conjunto de incentivos hábilmente ideados por Ford, como el aumento del salario y la reducción de las horas semanales creando, de este modo, una capacidad adquisitiva y un «tiempo de consumo» para su producto. ${ }^{12}$ Tanto por sus objetivos como por su política de incentivos, SEAT representó, en cierto modo, un modelo de fordismo, ya que la empresa trató de fomentar una serie de ventajas entre sus trabajadores con el objetivo, no solo de neutralizar cualquier tipo de reivindicación, sino también de generar su identificación con una «marca de prestigio». ${ }^{13}$ Esto no impidió, como se verá más adelante, que SEAT, enarbolada como empresa «nacional», fuese un foco permanente de conflictividad laboral de los años sesenta.

En 1953 se lanzaba el modelo 1400, cuyo precio (128.000 pesetas más 16.600 de impuesto de lujo) lo convertía en un modelo asequible solo para las clases acomodadas. El contexto era el de una España netamente rural. El empleo en el sector primario representaba el $48 \% .{ }^{14} \mathrm{El}$ parque móvil era solo de 111.000 unidades,,$^{15}$ con un índice de un coche por cada 3.000 habitantes. ${ }^{16}$ La capacidad de producción de SEAT era de cinco unidades diarias, insuficientes para atender una demanda en aumento. En 1956, las peticiones se elevaban a 10.000 , lo que mostraba la existencia de un seg-

11 Gimeno, 2000, pp. 21-22.

12 Calabrese, 1996, p. 542.

13 Sobre la aplicación del modelo fordista a SEAT, véase Tappi, 2007.

14 Martín y Martínez, en Towson (ed.), 2007, p. 5.

15 Solé, 2001, p. 12.

16 Cassany y López, 1996, p. 22. No obstante, el retraso en la motorización del país se debió más a las tensiones políticas internas del régimen franquista que a la carencia de un proyecto para el impulso del vehículo, existente desde 1940 por el acuerdo entre Banco Urquijo y Fiat. San Román, 1995, p. 161 y Tappi, 2007, p. 105. 
mento de mercado en alza que vaticinaría el éxito de su siguiente modelo, el SEAT 600. La producción llegaría a cubrir la demanda, para lo que la fábrica de la Zona Franca de Barcelona aumentaría su plantilla desde los 925 empleados en 1953, hasta los 5.000 en $1957 .{ }^{17}$ Pese a este relativo éxito, disponer de un vehículo estaba solo al alcance de una minoría, por lo que el objetivo de SEAT era el de lanzar un segundo modelo a un precio más competitivo, dirigido a un público más modesto.

$\mathrm{El}$ antecesor del SEAT 600 fue precisamente el Fiat 500 «Topolino». Este modelo, sin embargo, presentaba muchas limitaciones, como su escasa capacidad, pues solo permitía como máximo dos adultos y dos niños. Dante Giacosa se apoyó en este modelo para diseñar un «utilitario», concebido como un coche pequeño, resistente, de fácil manejo y que permitiese desplazamientos cortos.

El Fiat 600 fue presentado en el Salón del Automóvil de la Feria de Ginebra en 1955, donde tuvo una muy favorable acogida. Animada por el éxito, el 15 de octubre de 1955 SEAT contrató con Fiat la licencia para fabricar el 600, de cuyo prototipo se realizó un coche final, con una cilindrada de 633 cc y potencia de 19 CV. Este Fiat 600, gemelo del SEAT, fue presentado en la Feria de Muestras de Barcelona de 1957. La única diferencia fueron las ventanillas, antideslizantes en el modelo original, y que fueron sustituidas por cristales descendentes en el Seiscientos, y algunos retoques técnicos. ${ }^{18}$

El 27 de junio de 1957 comenzaba la fabricación del SEAT 600 en la Zona Franca de Barcelona. El primer modelo, conocido comercialmente como «Normal», tenía una cilindrada de $633 \mathrm{cc}$, una potencia de $21,5 \mathrm{CV}$ y alcanzaba una velocidad máxima de 95 kilómetros por hora. Aunque estaba concebido para cuatro personas, su capacidad era mayor, lo que permitía darle un uso familiar. Este será, precisamente, uno de sus argumentos publicitarios: «Con SEAT no tendrá que sufrir la falta de espacio vital, porque SEAT concebió (sic) sus vehículos pensando en Vd. y toda su familia». ${ }^{19}$

17 Cassany y López, 1996 p. 72.

18 Solé, 2001, p. 38.

19 Anuncio inserto en Triunfo, 29 de junio de 1963, p. 3. «Magnífico prototipo de vehículo económico, responde a la necesidad de una zona muy amplia de usuarios y viene, en teoría, a lanzar un puente entre muchos clientes en potencia de motocicletas y sidecares, ampliado a la escala de vehículo familiar y con un relativo bajo presupuesto de gastos». Así se presentaba en el diario deportivo Marca, que calificaba al «pequeño Seat 600», como «el gran personaje de la producción española» (Marca, 1 de febrero de 1959 , p. 16). 
Sin embargo, pese a que el Seiscientos ha pasado a la historia como uno de los coches más populares, el precio, 65.000 pesetas (390 $€$ en la actualidad) no estaba al alcance de todos. En 1957, año del comienzo de su fabricación, la renta per cápita en España era de 18.472 pesetas. La compra de un Seiscientos suponía cuarenta y dos meses de trabajo,$^{20}$ a lo que se sumaba que el precio final del vehículo se veía incrementado por un conjunto de costes adicionales, como el impuesto de lujo (11.200 pesetas), más los intermedios, hasta la puesta en circulación. Pese a ello, las peticiones rebasaron la capacidad de producción. En 1958, la fábrica generaba 2.586 unidades, si bien, la previsión era aumentar la producción hasta las 10.000-12.000 unidades. Sin embargo, las demandas en el primer año llegaron hasta las 100.000, lo que promovió que SEAT incrementase su plantilla y maquinaria. ${ }^{21} \mathrm{~A}$ las listas de espera había que añadir el proceso para acceder a la compra, para lo que había que realizar una solicitud con los datos personales y profesionales, junto con un documento bancario o notarial que avalase la firma. Este informe preliminar costaba 3.500 pesetas. Si la solicitud era aceptada, debía efectuarse un ingreso de 33.250 pesetas a cuenta del importe total del vehículo. En seis meses, SEAT notificaba la disponibilidad del coche, momento en el que se hacía efectivo el pago del impuesto de lujo. El automóvil salía a circulación con una matrícula provisional de color verde, que debía ser homologada por un ingeniero industrial, para lo que había que pagar 12.150 pesetas, con las que se obtenía la matrícula blanca definitiva. Los gastos tenían que realizarse al contado, lo que suponía que el cliente debía tener una garantía de solvencia.

En 1963, la factoría de la Zona Franca lanzaba una nueva versión del Seiscientos mejorada. El $600 \mathrm{D}$ aumentaba su potencia con respecto al «Normal» y pasaba de 633 cc y $21,5 \mathrm{CV}$ a 767 cc y $29 \mathrm{CV}$, sin variar el consumo. Se perfeccionaba el sistema de frenado y se incorporaba un radiador sobredimensionado para acabar con el recalentamiento del motor, uno de sus principales problemas. A estas alturas, el éxito del Seiscientos era indudable: de las 36.302 unidades fabricadas en 1963 se pasó a casi el doble en 1964, 61.091; cifra que se fue incrementando, hasta alcanzar las 71.608 en 1968, pese a que en 1966, SEAT había lanzado un nuevo modelo, el 850. El Seiscientos se apoderaba del paisaje español,

20 Gimeno, 2000, p. 114.

21 Cassany y López, 1996, p. 53. 
tal y como rezaba en uno de los slogans que acompañaba a la marca en la prensa: «SEAT ha dado "vida" a las carreteras españolas» 22 y fue proclamado «Figura Nacional» 1967 en el diario Pueblo. ${ }^{23}$ El periodo coincidía con el boom del tráfico en España, en el que los modelos SEAT acaparaban la mayoría de los vehículos en circulación. Un anuncio de 1962 proclamaba su éxito como reclamo comercial: «200.000 automóviles SEAT circulan en España», ${ }^{24}$ mientras que otro de 1963 planteaba: «¿Por qué SEAT ha conquistado tan fabulosa popularidad?», «alta calidad y rendimiento», argumentaban como estrategia publicitaria. ${ }^{25}$ En 1967, circulaban 1.330.000 turismos, de los que 682.000 (51\%) eran SEAT, en su mayoría Seiscientos ${ }^{26}$ fenómeno que fue en aumento, pues en 1969, las matriculaciones sobrepasaban las 400.000, de las que SEAT representaba el $62 \%,{ }^{27}$ en competencia con Barreiros, Renault, Authi y Citroën, que incrementaron su presencia en España ante el notable auge del consumo de vehículos..$^{28}$

El impulso del Seiscientos se vio también favorecido por las facilidades de la propia casa SEAT para adquirirlo. Además de aumentar su producción, rebajó el precio de 65.000 pesetas en 1963 a 63.000 en 1964, precio que mantendría hasta 1969 , en un contexto en el que la economía española seguía creciendo a un alto ritmo.$^{29}$ La creciente competencia de un sector en expansión impulsó también la creación en 1967 de Fiseat, la financiera de SEAT, que agilizaba la tramitación del proceso para la compra de un vehículo y promovía el sistema de pago a plazos. Fiseat creó una red asistencial encargada, no solo de la venta de vehículos, sino también de facilitar el acceso a recambios originales y ampliar la red de talleres autorizados, además de impulsar una red comercial que tuvo muy buena acogida. ${ }^{30} \mathrm{Su}$ funcionamiento fue tan eficiente que uno de los co-

22 ABC, 26 de febrero de 1962, pág. 46.

${ }^{23}$ Gimeno, 2000, p. 72.

${ }^{24}$ Triunfo, 10 de noviembre de 1962, p. 2.

25 Triunfo, 18 de mayo de 1963, p. 91.

${ }^{26}$ Gimeno, 2000, p. 65.

27 Ibid., p. 72.

28 Sobre la competitividad entre la industria automovilística francesa y alemana por penetrar en el mercado español, véanse De la Torre, 2011, pp. 181-206 y Catalan, 2000.

${ }^{29}$ Entre el periodo de 1959 y 1974, el PIB subió al 6,92 \%. Cfr. De la Escosura, citado en Towson (ed.), 2007, p. 4. Por otro lado, la renta per cápita pasó de las 21.365 pesetas a 111.437, en 1973. Véanse Solé, 2001, p. 73 y Gimeno, 2000, p. 114.

30 Cassany y López, 1996, p. 62. 
mentarios populares del momento era que los repuestos del Seiscientos se encontraban hasta en las farmacias.

En 1969 se lanzaba el modelo SEAT 600 E, en el que la principal modificación era el sistema de apertura de puertas hacia adelante. Fue el más comercializado, aunque el incremento del nivel de vida familiar hizo que progresivamente se prefiriesen otros modelos. Pese a ello y a la subida del precio (en 1970 pasaría ya a 68.100 pesetas), seguía siendo uno de los vehículos más demandados, convertido en muchos casos en el «segundo coche» familiar, destinado en su mayoría a la mujer. Por entonces, también se había desarrollado un mercado de segunda mano, con precios más bajos que los de fábrica, lo que promocionó definitivamente la extensión del Seiscientos entre las clases populares. Convertido en objeto de deseo para amplios sectores sociales, el Seiscientos comenzó a forjar su leyenda como «el coche más duro» y «capaz de todo», que acompañaría a su imagen publicitaria. «El Seat «600» irá de cabeza al cielo de los automóviles, porque está formado en la adversidad más notoria de las grandes rutas españolas», aseguraba Alfonso Paso en Madrid. ${ }^{31}$ La figura de un médico rural en un paisaje invernal, presto a atender una urgencia en su Seiscientos, resultaba un compendio de sus virtudes, por su polivalencia para el campo y para la ciudad y por su doble uso, privado y profesional ${ }^{32}$ y hasta por su función social. Aunaba, pues, los valores del desarrollismo tecnocrático y la idea de «servicio», tan grata a los sectores azules del régimen, sin descuidar los acendrados principios del nacionalcatolicismo, la familia entre ellos. Era, en suma, un factor de cohesión social y territorial y, al mismo tiempo, de consenso político entre las familias políticas del régimen.

La última versión $600 \mathrm{~L}$, aparecida en 1972, apenas duró un año y su fabricación se compatibilizó con el anterior modelo E hasta 1973, año en el que SEAT cesó la producción del Seiscientos, pese a seguir siendo un modelo muy solicitado. La promoción publicitaria del nuevo modelo ya desvelaba la evolución de las preferencias de los conductores por vehículos técnica y estéticamente más avanzados, así como la problemática del tráfico urbano surgida con el incremento del uso del automóvil. El nuevo Seiscientos trataba de dar cabida a ambos aspectos, al presentarse como

31 «La pobrecita autopista», por Alfonso Paso, en Madrid, 27 de septiembre de 1966, p. 3.

32 Publicidad del Seiscientos inserta en La Vanguardia, 7 de marzo de 1971, p. 18. Anuncio que tuvo también una versión para televisión: https://www.youtube.com/ watch? $\mathrm{v}=$ BnoraqbFEqs (Consulta realizada el 20 de agosto de 2018). 
vehículo de transición «para los que van a comprar su primer coche» y como utilitario «pequeño, cómodo, potente y manejable», atendiendo a su inspiración esencial, «para callejear por la ciudad». ${ }^{33}$ Como coche de transición o como segundo vehículo «para los que tienen un coche grande. En el garaje», ${ }^{34}$ el Seiscientos estaba quedando paulatinamente relegado «como coche de ciudad» para una sociedad que cada vez viajaba más. Tres años antes, Fiat había dejado de fabricar el modelo 600, lo que pudo influir en la decisión de la dirección de SEAT de no comercializar un modelo obsolescente. ${ }^{35}$ La última unidad, que salía de fábrica el 3 de agosto de 1973, fue despedida con un slogan que resumía el éxito alcanzado: «Naciste príncipe, mueres rey», convertido, además, en protagonista de múltiples versiones, como el descapotable, el 800, con cuatro puertas, el Formichetta ${ }^{36}$ el playera o el comercial, entre otras tantas. ${ }^{37}$

Convertido en reclamo publicitario por otras marcas, muchos suspiraron por lograr uno de los Seiscientos que todas las semanas regalaba el brandy Soberano, ${ }^{38}$ Avecrem, ${ }^{39}$ Gaceta Ilustrada ${ }^{40}$ o la marca láctea catalana Nieve.$^{41}$ La profusión de sorteos de Seiscientos fue satirizada por $L a$ Codorniz, que prometía un premio de «un SEAT 600 y una nevera entre los lectores que demuestren que las cosas no son como son». ${ }^{42}$

El Seiscientos pasó a ser el coche de moda, que lucían estrellas populares del mundo del toreo, como Juan Benítez «El Cordobés»; del deporte, como el campeón de motociclismo Ángel Nieto o el futbolista José María Martínez «Pirri»; del espectáculo, como la actriz Lina Morgan ${ }^{43}$ o de alta

33 Anuncios publicitarios publicados en La Vanguardia, 3 de noviembre de 1972, p. 50 y 23 de noviembre de 1972, p. 42.

${ }_{34}$ La Vanguardia, 23 de noviembre de 1972, p. 42.

35 Solé, 2001, p. 73.

36 «iLa furgoneta más utilitaria! Pequeñita, ¡pero cumplidora!...», se promocionaba en un anuncio en Madrid, 23 de septiembre de 1966, p. 8.

37 La marca española había iniciado también su expansión en 1965 hacia el exterior, a través de la exportación a países como Colombia, Argentina, Holanda, Portugal y Finlandia, donde el Seiscientos fue el coche más vendido en 1972. Gimeno, 2000, p. 75; Catalan, 2006, pp. 167-169 y Catalan, en Balfour, 2012, pp. 66-67.

38 Triunfo, 11 de agosto de 1962, p. 46.

39 Triunfo, 11 de febrero de 1963, p. 46.

40 La Vanguardia, 4 de febrero de 1971, p. 71.

${ }^{41}$;Hola!', 21 de enero de 1961, p. 8.

42 «Nuestro raro editorial: ¡Que quiten las desgravaciones!», La Codorniz, 3 de marzo de 1963 ,p. 2.

${ }^{43}$ https://elpais.com/economia/2007/06/27/actualidad/1182929574_850215.html 
sociedad, como la princesa iraní Soraya, durante su estancia en Ibiza, ${ }^{44}$ lo que alimentó el deseo de imitar a los ídolos sociales del momento. También fue el coche de escritores como Álvaro Pombo y José Agustín Goytisolo, del dibujante Antonio Mingote ${ }^{45}$ o de políticos, como Pasqual Maragall, futuro presidente de la Generalitat.

\section{El Seiscientos, aquellos maravillosos años}

El Seiscientos ha quedado indisolublemente unido en el imaginario español a los cambios que España experimentó a partir de los años sesenta. Las reformas económicas impulsadas a partir del Plan de Estabilización y los Planes de Desarrollo lograron un crecimiento económico que promovería también cambios sociales y culturales significativos que facilitarían el tránsito hacia la democracia. Algo que ya fue capaz de vaticinar Luis Araquistáin desde el exilio a la temprana fecha de 1958 cuando, en una carta a Gregorio Marañón, reconocía de forma anticipada el «milagro español» y las posibles consecuencias que este avance económico podía tener para un cambio histórico en el país, tantas veces frustrado por falta de base:

«Es asombrosa esa España que está surgiendo, sobre todo en su estructura económica. Se está haciendo una revolución industrial que nunca se había hecho y por la que tanto suspirábamos, porque de ella, del enriquecimiento del país, depende el remedio de muchos otros problemas de la infraestructura». ${ }^{46}$

Un artículo de Juan Goytisolo servía a Gregorio Morán para interpretar la trascendencia de estos cambios desde el prisma del Partido Comunista en el exilio:

«El obrero conduciendo un 600 por la autopista de Castelldefels [en Barcelona] se convirtió para Carrillo y el partido en el símbolo de la política revisionista y neocapitalista de 'los dos efe' [Fernando Claudín y Jorge Semprún, a. Federico Sánchez]». ${ }^{47}$

44 ;Hola!, 2 de marzo de 1963, p. 25.

45 http://www.elmundo.es/motor/MVnumeros/97/MV006/MV006mingote.html

46 Fuentes, 2002, p. 227.

47 Comentario de Gregorio Morán relativo a un artículo de Juan Goytisolo publicado en L'Express, 4 de abril de 1964. Cfr. Morán, 2017, p. 686. 
Santos Juliá, parafraseando a quien fuese vicecomisario de la Comisaría del Plan de Desarrollo, Fabián Estapé, sintetiza el significado de estos cambios en la idea de que el verdadero artífice de la transición democrática fue el seiscientos, no Suárez, ${ }^{48}$ aunque, matiza, la democracia no fuese, ni mucho menos, el objetivo del gobierno de los tecnócratas.

No obstante, resulta demasiado simplista hacer radicar en la política económica de los tecnócratas el éxito de la transición, teoría que fue sostenida oportunamente por las élites franquistas posteriormente, y que tendría en Gonzalo Fernández de la Mora uno de sus más firmes defensores. ${ }^{49}$

Los ejes en los que se sustentó el conocido como «milagro económico» fueron la inversión extranjera, la emigración y el turismo. El sector industrial recibió un impulso significativo con la entrada de inversión exterior que atrajo mano de obra desde el ámbito rural al urbano. La movilidad interna promovió un notable proceso de urbanización. ${ }^{50}$

El desarrollo industrial y económico fomentó también la aparición de la sociedad de consumo en un contexto favorable en el que el crecimiento del empleo en los sectores industrial y de servicios incrementó el nivel de ingresos de los trabajadores e impulsó el surgimiento de una clase media urbana. Pese a la rígida estructura sindical del régimen, el periodo se caracterizó por una mejora de las condiciones laborales, como el horario regularizado y el derecho a vacaciones anuales. ${ }^{51}$ Poder adquisi-

48 Juliá, en Fusi et. al., 2005, p. 70.

49 Fernández de la Mora fue uno de los valedores de la tecnocracia, inspirada en su idea acerca de la necesidad de un pragmatismo político frente a la pérdida de eficacia de las ideologías, tesis que recogía en una de sus obras más conocidas, El crepúsculo de las ideologías (1965). Un año antes escribía: «De la política como arte y como retórica vamos a la política de la ciencia y como técnica (...). Al retoricismo urge jubilarlo con toda consideración, pero inexorablemente». «La nueva política», Gonzalo Fernández de la Mora, $A B C, 17$ de noviembre de 1964, p. 3 .

${ }^{50} \mathrm{La}$ provincia de Madrid, por ejemplo, duplicó prácticamente su población desde 1.926.311 habitantes en 1950 a 3.792.561, en 1970. Censo de población, 1950 y 1970. Poblaciones de derecho y de hecho de los municipios españoles. Instituto Nacional de Estadística (INE). Disponible en línea, en http://www.ine.es/inebaseweb/pdfDispacher. do?td=125313\&ext=.pdf para el año 1950 y en http://www.ine.es/inebaseweb/pdfDispacher.do?td=139990\&ext=.pdf, para 1970. Este crecimiento fue también considerable en Barcelona en ese mismo periodo, donde se pasó de los 2.232.119 habitantes en 1950 a 3.929.194 en 1970. Cfr. http://www.ine.es/inebaseweb/pdfDispacher.do?td=125293\&ext=. pdf, para el censo de población en la provincia de Barcelona en el año 1950 y en http:// www.ine.es/inebaseweb/pdfDispacher.do?td=139970\&ext=.pdf, en el caso de 1970. (Consulta realizada el 14 de febrero de 2018)

51 Bernecker, en Towson (ed.), 2007, p. 59. 
tivo y tiempo de ocio fueron dos elementos que favorecieron el consumo. Indudablemente, estos cambios insuflaron en muchos españoles el deseo de prosperar social y económicamente. Disponer de ciertos bienes materiales era, además, un símbolo de status social: la compra de un piso, de un coche propio, de un televisor o de una serie de electrodomésticos que facilitaban la vida cotidiana. La aspiración a un coche se hizo evidente, pues si en 1961 había 12 coches por cada mil habitantes, en 1971 esta cifra subía a 71, si bien, aún estaba alejada de países como Francia, con 245 coches por cada mil habitantes en 1971 y Gran Bretaña, con $213 .{ }^{52}$ «El coche - declaraba Vázquez Montalbán - ha sido la gran panacea de la prosperidad».53

Televisor y vehículo se convirtieron en los dos principales símbolos de nuevo status, con connotaciones también en el ámbito familiar. Si la televisión era un elemento aglutinante de la familia en el hogar, el coche lo era fuera, en la carretera y en las vacaciones, inaugurando nuevas costumbres sociales.

Pese a la expansión del consumo de coches y electrodomésticos, para una familia media, adquirir cualquiera de estos productos implicaba un considerable esfuerzo económico. «No es necesario comparar cifras, pero la sociedad "del bienestar" no es en España el disfrute de una amplia serie de bienes, sino más bien la imposición de un clima psicológico que hace creer que esos productos son asequibles a todos», matizaba Pedro Altares en un crítico artículo contra el fenómeno consumista que mostraba numerosos desequilibrios, a la par que actuaba como adormidera de la sociedad frente a cuestiones de mayor trasfondo. «Cuando se examinan las diferencias en las tiradas de los libros (...) cuando pueden verse los enjambres de "seiscientos" huir los domingos de la aglomeración ciudadana, para caer en otra mayor alrededor de pequeños charcos de agua (la gasolina es cara) a escasos kilómetros de la ciudad, es inevitable pensar que ese consumo "a la española" puede resultar el plato de lentejas por el que muchos están a punto de vender muchas inquietudes». ${ }^{54}$

La sociedad española, sobre todo, la urbana, se entregó a ese clima de consumismo. En 1960, el promedio de meses de trabajo para comprar un

52 Buchanan, en Towson (ed.), 2007, p. 79. No obstante, este índice se incrementaría en 1975, cuando la cifra era de 111 coches por cada mil habitantes.

53 Vázquez, 2003, p. 158.

54 «La fábula del plato de lentejas o el consumo a la española», Pedro Altares, Destino, 31 de agosto de 1968, pp. 34-35. 
Seiscientos se había reducido a treinta y nueve y descendió a veinticuatro en 1963 debido, entre otras causas, a la bajada del precio del vehículo mientras la renta per cápita se incrementaba. ${ }^{55}$ El tiempo de ahorro se aminoró progresivamente, pero no eliminó la necesidad de un esfuerzo para lograrlo. El precio, por ejemplo, de un aparato de televisión Marconi era de 22.450 pesetas, ${ }^{56}$ cifra muy elevada, que inspiraría historias como El televisor (1974), de Narciso Ibáñez Serrador, en el que un padre de familia, interpretado por Narciso Ibáñez Menta, se obsesiona con la compra de una televisión, con terroríficas consecuencias. Contar con estos nuevos elementos de consumo era un símbolo de status, pero también de bienestar y de modernidad. Tal y como ironizaba Luis Carandell, «se ideó el sistema de los conocidos plazos mediante el cual, el español de la nueva democracia consumista podía adquirir los más variados artefactos y chirimbolos (...) aún a riesgo de reducir la dieta alimenticia y aún a costa de recurrir al más desaforado pluriempleo». ${ }^{57} \mathrm{La}$ Codorniz ironizaba sobre el éxito del Seiscientos, pese a ese sacrificio económico: «Es un hombre muy original - se leía en uno de sus chistes- A pesar de ganar 8.000 pesetas al mes, todavía no se ha comprado un Seat $600 » .^{58}$

En un contexto de apreciables cambios, el Seiscientos simbolizó para muchos españoles su participación en ese proceso de modernización, pero también el acceso a elementos que hasta hacía poco representaban un lujo solo al alcance de una minoría. El Seiscientos implicaba a la vez equipararse con un sector social y económico superior y diferenciarse de una mayoría menesterosa, aunque su posesión se extendiese paulatinamente hacia sectores más modestos que, a su vez, experimentaron ese mismo sentimiento de elevación social y la «satisfacción de tener coche», tal y como rezaba uno de los anuncios publicitarios de SEAT en $1963 .{ }^{59}$ Esta «popularización» del Seiscientos representó asimismo un cambio en las costumbres: la disponibilidad de un vehículo permitía el desplazamiento hacia lugares desconocidos y despertó el interés de muchos españoles por ampliar su perímetro geográfico más allá de su cotidianidad. La disposición de mayor tiempo libre para el ocio, debido a la regularización de la semana laboral y las vacaciones anuales, impulsó a los españoles a

\footnotetext{
55 Gimeno, 2000, p. 114.

56 Triunfo, 23 de junio de 1962, p. 62.

57 Luis Carandell, «El tercer mundo de Madrid», Triunfo, 8 de junio de 1968, p. 37.

58 La Codorniz, 2 de septiembre de 1962, p. 8.

59 Triunfo, 23 de febrero de 1963, p. 35 y 9 de marzo de 1963, p. 35.
} 
lanzarse hacia los viajes turísticos de fin de semana y, progresivamente, a las vacaciones estivales en zonas costeras. ${ }^{60} \mathrm{La}$ ampliación de las infraestructuras viales, sobre todo, en los enclaves turísticos, contribuyó al crecimiento de esta nueva práctica social de consumo. «El automóvil es hoy una de las mayores evasiones, uno de los alicientes de distracción mayores del ser humano», reflexionaba José Pla ${ }^{61}$ «Uno se pregunta a dónde van, de dónde vienen y qué raro descanso es éste de turistas y veraneantes que les obliga a estar sobre el volante cada día y a las horas más intempestivas.Y es que simplemente ha caído en la esclavitud, en la constante tentación, en el vicio de la movilidad», concluía Néstor Luján. ${ }^{62}$

$\mathrm{El}$ «dominguero» inspiró canciones populares, como la que a principios de los sesenta dedicó Moncho Alpuente al «hombre del 600», en la que caricaturizaba esta forma de escapismo social que daba sentido a la vida del dominguero como «hombre nuevo» del desarrollismo («la carretera nacional es tuya»).

Se inauguraban con ello las masivas salidas del fin de semana y surgía también la figura del «dominguero», cuya acepción peyorativa, según el Diccionario de la Real Academia Española, se aplica al conductor «inexperto o lento», aunque con el tiempo esta connotación se haya extendido a un comportamiento social concreto. Esta nueva práctica puso de manifiesto el avance del proceso de secularización social: las excursiones dominicales sustituyeron a las «obligaciones» religiosas, que quedaron progresivamente relegadas.

La ampliación del núcleo de interés geográfico conllevó, además, la promoción de otros aspectos importantes, como fueron la conexión entre el mundo rural y el urbano y el contacto con los turistas que llenaban las playas, cuyo comportamiento e indumentaria, sobre todo de baño, eran distintas. Para muchos turistas nacionales, los extranjeros representaban precisamente la modernidad y la liberación en las costumbres que España todavía no había iniciado, mientras que para muchos jóvenes eran un modelo, si no a imitar sí, al menos, a asemejarse, dado el estrecho corsé impuesto por las costumbres puritanas de la Iglesia.

${ }^{60}$ Con el título de «La impresionante salida de Barcelona», la revista Destino dedicaba su portada del 2 de julio de 1966 al inicio de las vacaciones. La imagen mostraba largas hileras de coches, entre las que, prácticamente la mitad eran modelos Seiscientos.

61 «Sobre las maneras de andar por el mundo», José Pla, Destino, 28 de agosto de 1966, p. 18.

62 «Los accidentes de circulación», por Néstor, Destino, 31 de agosto de 1968, p. 16. 
Otro de los conceptos que experimento una modificación fue el del espacio colectivo. El desarrollo del urbanismo implicó un cambio en la dimensión del espacio público. Frente al entorno rural, en el que el desarrollo llegaría de forma retardada, la organización de los espacios e infraestructuras urbanos se habían realizado hasta el momento bajo un concepto de colectividad, propia de un sistema autoritario, con el fomento de una política de transporte colectivo frente al individual. El uso del vehículo no solo abrió el concepto de propiedad privada, sino que a partir de su uso, el individuo (y, por ende, la unidad familiar) tomó posesión de ese espacio público. Esto supuso, además, el crecimiento de la movilidad individual frente a la colectiva. ${ }^{63}$ Como resultado de ese auge de la movilidad, el Estado tuvo que desarrollar políticas destinadas al ordenamiento del tráfico, que comienza a representar un problema en las grandes ciudades, cuyas infraestructuras no estaban preparadas para la asimilación del nuevo fenómeno. En 1959 se creaba la Jefatura Central de Tráfico. ${ }^{64}$ Los principales núcleos urbanos comenzaron a acusar el crecimiento acelerado de vehículos. «El número de coches ha aumentado considerablemente - aseguraba Pla en Destino - . En la época que vivimos, levantar un poco la cabeza quiere decir hacerse con un coche rápidamente», ${ }^{65}$ con el consiguiente problema urbano. «En un espacio de tiempo relativamente escaso, - continuaba - Barcelona, las calles de Barcelona se han convertido en un inmenso campo de aparcamiento de coches. (...) El Ayuntamiento ha ido quitando terreno a los peatones - calzadas, aceras, etcétera - y lo ha ido dando a los automovilistas». ${ }^{66} \mathrm{La}$ misma situación se planteaba en Madrid. «La creciente industrialización del país, las mayores posibilidades económicas de sus clases populares y el lanzamiento de vehículos acomodados a los niveles del hombre medio, han transformado las calles de la ciudad en un verdadero laberinto», se concluía en el diario

63 Calabrese, 1996, p. 549.

${ }^{64}$ Ley $47 / 1959$, de 30 de julio, sobre regulación de la competencia en materia de tráfico en el territorio nacional.

65 «Barcelona, como aparcamiento», José Pla, Destino, 11 de abril de 1964, p. 29.

${ }^{66}$ Una viñeta, en la que figuraban varios Seiscientos y 1400, jugaba con la denominación de estos extendidos modelos de SEAT para criticar las consecuencias del aumento de coches en la capital catalana: « Has visto lo que maquinan los amantes del motor? ¡Convertir en autódromo permanente los jardines de Montjuich!», se quejaba en tono humorístico uno de los personajes. «600 + 1400: El año 2000, ¿qué harán?, por JIP, en Destino, 29 de mayo de 1965 , p. 24. 
Madrid ${ }^{67}$ El tráfico se convirtió en un tema de preocupación «para todo el mundo», se aseguraba en La Nueva España. "Porque las personas se clasifican inevitablemente en peatones o en «seatones». ${ }^{68}$ Una portada de La Codorniz, ya en 1961, satirizaba sobre el nuevo fenómeno urbano. En «Estampas madrileñas: Los atascos», se mostraba una larga hilera de los más variopintos coches y algún sidecar, en la que un conductor aprovechaba para echarse un solitario. Unas páginas más adelante, la viñeta de un vehículo armado con unos enormes dientes avanzaba terriblemente sobre los viandantes: «Es la última palabra - se aclaraba- - No necesita de gasolina. Se alimenta de peatones». ${ }^{69} \mathrm{El}$ caos circulatorio y la difícil convivencia inicial entre coches y peatones había sido ya objeto de humor en la clarividente novela de Wenceslao Fernández Flores El hombre que compró un automóvil, publicada en 1932, y su inolvidable pasaje del peatón refugiado del aluvión de coches en un islote, donde coincide con otro náufrago de la selva automovilística. La novedosa y caótica situación promovería campañas de civismo ${ }^{70}$ en las que no se escatimó tampoco el humor y el recurso a la cultura popular, con términos tan extendidos como el de «seatón». ${ }^{71}$

Aparecía, asimismo, otro fenómeno anejo, como fue la siniestralidad vial. «La carretera mata hoy más que la tuberculosis, más que el cáncer, más que el temible infarto de miocardio», señalaba otro artículo de 1967, que ponía de manifiesto la preocupación ante una de las consecuencias de la desorbitada proliferación de vehículos:

${ }^{67}$ Madrid, 27 de septiembre de 1966, p. 9.

68 La Nueva España, 21 de abril de 1960, p. 1.

${ }^{69}$ La Codorniz, 29 de enero de 1961, pp. 1 y 10.

70 Bajo el lema «Para una Barcelona mejor», el Ayuntamiento de la capital impulsó una campaña en la que solicitaba el respeto entre coches y peatones. El mensaje se acompañó de una imagen en la que, además de otros vehículos, dos Seiscientos figuraban en primera línea ante un paso de peatones. Véase Destino, 5 de diciembre de 1964, p. 4.

71 Con motivo de las festividades navideñas, Destino insertaba un poema, que era todo un compendio de esa cultura popular surgida en torno al vehículo y al tráfico: «Todo aquel que bien se estima/en llegando Navidad/ni a su enemigo escatima/una prueba de amistad/ Así pues - y quedan pocos - aquel que no es 'seatón'/ni va en moto 'a lo loco'/ni manipula un camión/ni coche de importación/espera quien se lo traiga/y su humilde condición/ le impide tener un 'haiga'/ni por ahí bebe los vientos/cual corredor cabal/y en el popular 'seiscientos'/fulmina la Diagonal». Fragmento de la felicitación navideña inserta en Destino, 19 de diciembre de 1964, p. 127. 
El 31 de julio del año pasado hubo más automovilistas heridos en nuestro país que soldados israelíes lesionados en la reciente guerra relámpago de Oriente Medio (...). Ha progresado más de prisa (sic) la máquina que la carretera, y al avance fabuloso de los motores no ha correspondido análogo adelanto en la capacidad humana para gobernar esos poderosos ingenios, autogobernándose. Por el contrario, la fabricación y venta acelerada de automóviles - en nuestro país el parque automóvil ha llegado rapidísimamente a la matrícula seiscientos mil sólo en Madrid y Barcelona - ha lanzado a la carretera cientos de miles de conductores inexpertos». ${ }^{72}$

En 1961 se inauguraban los Anuarios Estadísticos de Accidentes de Circulación ${ }^{73}$ y se impulsaron campañas de concienciación, que ya se inauguraron en 1960 y que proclamó el 6 de mayo como el «Día sin accidentes». ${ }^{74}$

La popularización del Seiscientos alcanzó también a la mujer, en un contexto en el que cuestiones como el divorcio, el control de la natalidad y la liberación sexual estaban en España muy alejadas aún de los planteamientos occidentales del momento. Pese a ello, en los años sesenta comienza el proceso de incorporación de la mujer al mundo laboral en puestos fundamentalmente administrativos, pero su interés por disponer de una formación superior se manifestó en el crecimiento de la presencia femenina en las aulas universitarias. Un spot publicitario en el NO-DO en 1957 presentaba al Seiscientos como el coche para todos. Un utilitario hecho por hombres, pero cuyo «manejo fácil» y «aprendizaje

72 ABC, 27 de julio de 1967, p. 28

${ }^{73}$ En el periodo de 1961 a 1973 , las cifras de accidentes se dispararon desde los 21.131 , contabilizados en 1961, hasta los 98.890 , de 1973. El aumento fue proporcionalmente superior al incremento del parque móvil nacional, desde 1.223.506 vehículos de 1961 hasta los 5.334.633, en 1973. Las ciudades que estadísticamente registraron más accidentes fueron las que experimentaron también un mayor crecimiento industrial o turístico. Barcelona y Madrid encabezaron esta siniestra lista seguidas, a gran distancia, de Valencia, Málaga y Vizcaya. Cfr. Anuarios Estadísticos de Accidentes de Circulación. 1961-1973.

74 Véase Hogar y Pueblo, 21 de abril de 1961, p. 4. Los mensajes para la prevención de accidentes se difundieron especialmente en la prensa oficial, con apelaciones a la responsabilidad del conductor ante el consumo de alcohol o a la prudencia. Algunos ejemplos de los mensajes, impulsados desde la Jefatura Central de Tráfico, pueden consultarse en Proa, 14 de abril de 1960, p. 4, La Nueva España, 3 de junio de 1960, p. 6 y en Madrid, 26 de septiembre de 1966, p. 11 y 10 de noviembre de 1966,p. 7. 
fácil» - se subrayaba - lo hacían idóneo para la mujer. ${ }^{75} \mathrm{Si}$ con la aparición de nuevos modelos el Seiscientos pasó a ser el «segundo coche», para la mayoría de las mujeres fue el primero, cedido en la familia para la esposa. También lo fue para las mujeres incorporadas al mundo laboral, para las que la disponibilidad de un salario propio significó el acceso a un objeto que simbolizaba una relativa emancipación. En 1961, el número de permisos concedidos a mujeres fue de $14.291 .{ }^{76}$ "A las mujeres, sobre todo, el automóvil les gusta apasionadamente», escribía $\mathrm{Pla}-$. A veces es posible encontrar un hombre fatigado del coche: las mujeres no se fatigan jamás - sobre todo si es propio - de esta clase de esperpento». ${ }^{77}$ En un contexto aún poco proclive a su liberación, conducir un Seiscientos era el camino más recto hacia su independencia, aunque aún lejana. «No nos engañemos: ella elige el color y conduce. Usted lleva el coche y paga. Así es la vida...», indicaba un anuncio de SEAT en 1968 protagonizado por un joven matrimonio, en el que parecía que las relaciones estaban cambiando y la mujer cada vez intervenía más en las decisiones. «Comprar un Seat es cosa de tres: su esposa, Vd. y Fiseat», se indicaba. ${ }^{78} \mathrm{El}$ anuncio estaba dirigido, sin embargo, al varón como comprador efectivo, mientras que el papel de la mujer se limitaba a la elección del color. Su posibilidad de conducir seguía dependiendo del marido.

Como «segundo coche» familiar, el Seiscientos fue asimismo el primer vehículo para muchos jóvenes, lo que influyó en sus ámbitos de sociabilidad y diversión. Estos cambios no pasaron desapercibidos para la marca que, dentro de su estrategia de marketing, apeló al segmento juvenil mostrando su capacidad de adaptación a «todas las edades», en un spot en el que un grupo de sonrientes jóvenes, tras una estancia campestre, recogía una tienda de campaña para subirla a la baca de un Seiscientos. ${ }^{79}$ (Véase Imagen 1).

75 https://www.youtube.com/watch?v=p_PSvAeQDOM y http://www.rtve.es/alacarta/ videos/documentales-b-n/coche-para-todos/2845434/ (Consultas realizadas el 19 de agosto de 2018)

76 Triunfo, 8 de septiembre de 1962, p. 14

77 «La época: las señoritas», por José Pla, Destino, 28 de agosto de 1965, p. 18.

78 ABC, 18 de agosto de 1968 , p. 38

79 La Vanguardia, 23 de junio de 1971, p. 58 


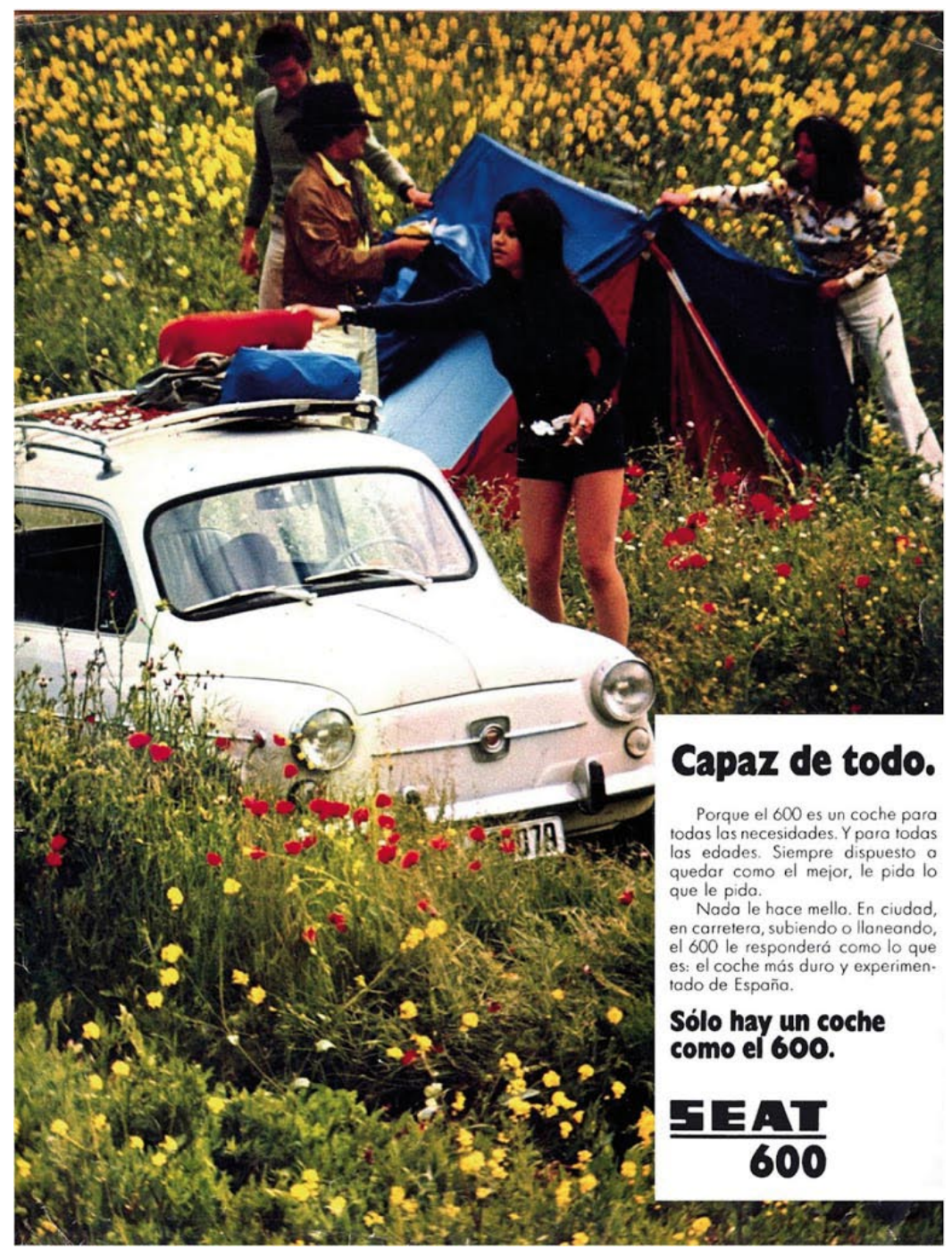

\section{Imagen 1}

Campaña publicitaria de SEAT en 1971 dirigida al sector juvenil 
El cine, como reflejo de la sociedad de la época, recogió todos estos aspectos. En Ya tenemos coche, película de 1958, dirigida por Julio Salvador, el argumento giraba en torno precisamente al Seiscientos y mostraba aspectos como el sacrificio económico de una familia madrileña de clase media para comprar el ansiado vehículo, el largo proceso burocrático para su adquisición y las vicisitudes del padre de familia en su viaje desde Barcelona, marcado por el recalentamiento del motor. El Seiscientos sería también el protagonista de un accidente en la película 091, Policía al habla, de 1960, dirigida por José María Forqué, quien lo utilizaba también como el vehículo de una de las parejas protagonistas de Accidente 703 (1962). Como modelo propio de la época, sirvió de ambientación en otras tantas películas del momento, como en las escenas iniciales de El cochecito (Marco Ferreri, 1960), La ciudad no es para mí (Pedro Lazaga, 1960), protagonizada por el popular Paco Martínez Soria y en la que se mostraba el caos circulatorio de Madrid, o en Sor Citröen (1967), del mismo director. También se convirtió en el suspirado coche del hijo mayor de La gran familia (Fernando Palacios, 1962), para quien disponer de una carrera universitaria corría parejo con poseer este coche.

\section{SEAT, escuela de antifranquismo}

Concebida como fábrica «nacional», SEAT se convirtió en el reflejo de los conflictos laborales que salpicaron la década de los sesenta, en los que diversos sectores comenzaron a desarrollar una actitud crítica hacia el sistema franquista.

Desde el primer momento, SEAT formó parte de los objetivos del régimen y, más particularmente, de Suances, de crear una industria automovilística de carácter nacional, a través del Instituto Nacional de Industria. No obstante, las fricciones internas en el propio seno del régimen postergaron su creación hasta 1950, año en el que surge la Sociedad Española de Automóviles de Turismo, S. A. (SEAT) ${ }^{80}$ El acuerdo suscrito con Fiat contemplaba que la marca italiana suministraría las partes para el montaje del vehículo, pero el INI negoció que también cedería la información técnica para que, tanto la fábrica como la industria auxiliar española, logra-

${ }^{80}$ Cassany y López, 1996, p. 22. Con un capital de seiscientos millones de pesetas, la distribución correspondió en su mayor parte al INI, con un 51\%, Fiat (7\%) y los bancos Urquijo, Bilbao Vizcaya, Español de Crédito, Hispanoamericano y Central (42\%) 
sen lo antes posible la fabricación completa de las partes del vehículo y de la maquinaria para la producción del mismo. El objetivo, por tanto, era el de conseguir progresivamente la independencia con respecto a la casa italiana, ${ }^{81}$ lo que supuso un esfuerzo inversor significativo. Fue precisamente a partir de 1957, coincidiendo con los inicios de la fabricación del Seiscientos, cuando SEAT evolucionó desde la concepción de «fábrica prestigio nacional» a la «fábrica - gran producción». ${ }^{82} \mathrm{El}$ incremento de la demanda de sus modelos planteó nuevas formas de organización y planificación de la producción que no solo pasaron por el aumento de su plantilla, sino también por la ampliación de las instalaciones de producción de la Zona Franca de Barcelona y la adquisición de maquinaria.

$\mathrm{Su}$ nacionalismo económico con, todavía, un cierto regusto autárquico, inspiró, de hecho, su publicidad en la prensa en 1961, en la que uno de sus reclamos publicitarios era precisamente su nacionalismo e independencia: «Una producción nacionalizada en un $97 \%$ por SEAT», proclamaba un anuncio. «SEAT prestigia la industria nacional». ${ }^{83}$ Lemas que apelaban al orgullo patrio como estrategia comercial, pero en los que se trataba también de ofrecer una imagen del avance industrial de la empresa $\mathrm{y}$, por ende, nacional, mediante la imagen de modernas instalaciones manejadas por uniformados operarios. Prestigio nacional y empleo fueron dos de los señuelos publicitarios de la empresa, pero SEAT también trabajó para la construcción de una imagen de marca bajo las consignas de «calidad» y «rendimiento» que acompañaban a todos sus anuncios. ${ }^{84}$ Otro de sus pilares propagandísticos sería el de lograr el acceso social a un vehículo, de acuerdo con uno de sus objetivos fundacionales. SEAT se presentó como «la industria nacional que ha puesto el automóvil como medio de trabajo y como complemento indispensable para una vida más cómoda, al alcance del mayor número de españoles» en un anuncio de 1963 que mostraba a dos jóvenes parejas orgullosas de sus Seiscientos en dos emblemáticos enclaves madrileños de neta simbología nacional, como eran la efigie de Felipe II en una de las escalinatas del Palacio Real y el puente de Segovia. ${ }^{85}$ (Véase Imagen 2).

\footnotetext{
81 Tappi, 2010, p. 41

82 Ibid., p. 29

83 ABC, 23 de mayo de 1961 , p. 10

${ }^{84}$ La Vanguardia, 28 de enero de 1962, p. 2 y Triunfo, 2 de marzo de 1963, p. 10

85 Triunfo, 23 de febrero de 1963 , p. 35 y 9 de marzo de 1963, p. 35, respectivamente.
} 


\section{SEAT ha divulgado en España la satisfacción de tener coche...}

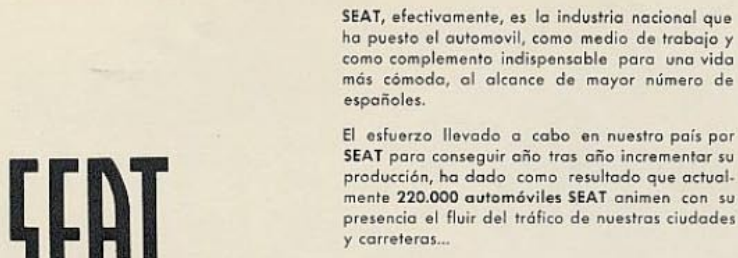

Sociedad Española de Automóviles de Turismo, S. A. Apartado 14.270-MADRID

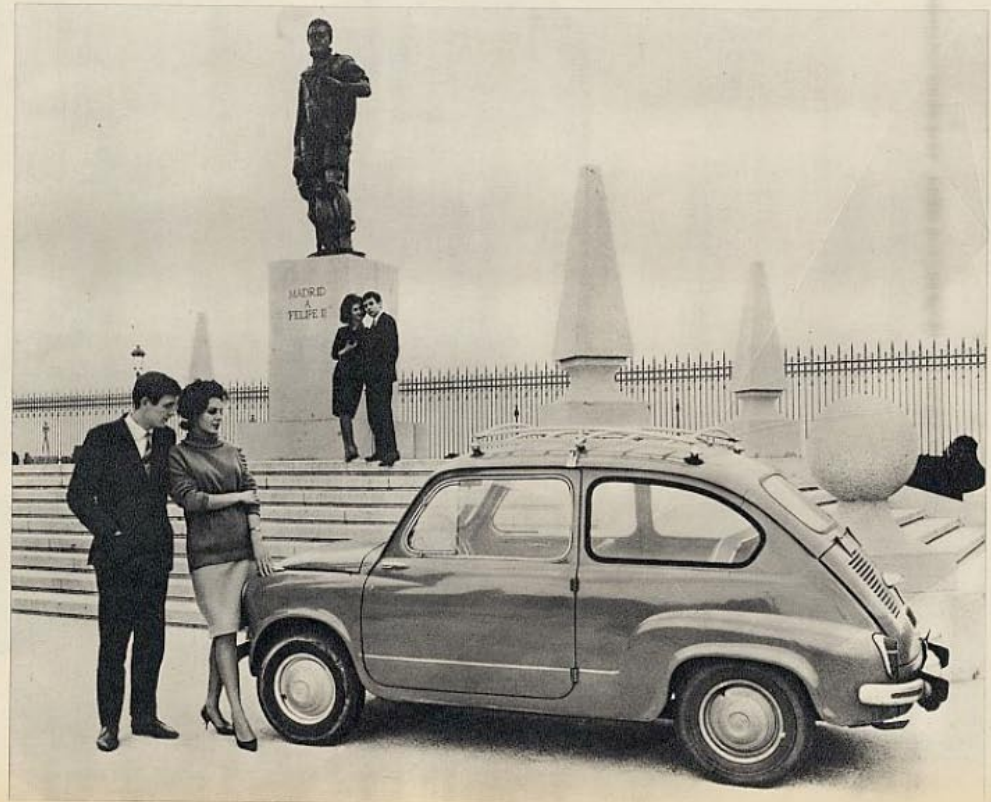

Imagen 2

Triunfo, 9 de marzo de 1963, p. 35 
La fabricación del Seiscientos se simultaneó con la del modelo 1400, aparecido en 1953, pero fue el primero el que se impuso en la producción. Desde 1958, el Seiscientos suponía en torno a los dos tercios de la producción de SEAT vendida en el mercado y logró prácticamente su nacionalización, salvo algunos componentes procedentes de Fiat. ${ }^{86}$ Será en el periodo de 1961 y 1963 cuando SEAT promueve el impulso de la factoría y la semiautomatización y automatización, y se produce el aumento de la producción, no solo del Seiscientos, sino también de los modelos 1500 y 850, aparecidos en 1963 y 1966, respectivamente. Con estos cambios se inauguraba la gran producción en serie.

El notable incremento de la plantilla, que en solo diez años pasó de los 5.000 trabajadores en 1957 a 14.500 en $1967,{ }^{87}$ supuso también el surgimiento de una serie de conflictos, pese a la política de control y de incentivos impulsada desde SEAT para tratar de anular cualquier reivindicación. Inicialmente, una de las pretensiones del régimen fue la de ubicar el centro de producción en una zona interior para promover su desarrollo. Sin embargo, finalmente se impuso la Zona Franca de Barcelona, por las ventajas fiscales, tecnológicas y logísticas ${ }^{88}$ En mayo de 1955 se inauguraba la Zona Franca de Barcelona. El objetivo era el de crear un núcleo industrial moderno, en el que se promoviesen empresas auxiliares, y que absorbiese a trabajadores (especialistas y obreros) procedentes de otros sectores en declive, como la siderurgia, la metalurgia o la mecánica. Otra de las estrategias del régimen para evitar problemas sindicales fue la de contratar a trabajadores procedentes del campo y de zonas y sectores con poca tradición de lucha obrera. La escasa cualificación inicial requerida permitía la integración de esta mano de obra para la que, además, suponía un ascenso económico y social significativo. ${ }^{89}$

La pretensión del régimen era hacer de SEAT una empresa modelo, como ejemplo de industria automovilística floreciente, generadora de puestos de trabajo y sin conflictividad. Producción, paz y prestigio ${ }^{90}$ fue-

86 Catalan, 2006, p. 153.

${ }^{87}$ Solé, 2001, p. 72

88 Sobre la decisión de la zona, no parece haber un consenso entre los diferentes investigadores. Véase San Román, 1995, p. 152; Tappi, 2007, p. 105, Catalan, 2006, p. 146 y Sanz, 2017, p. 9.

89 Miguélez, 1977 , p. 35

90 Ibid., p. 117. En 1962, SEAT recibía el premio de «Empresa ejemplar» por cumplimiento de objetivos. Sanz, 2017, p. 181. 
ron, por tanto, las consignas de la marca. Su funcionamiento se concibió de forma disciplinada, al estilo castrense, en el que el trabajo era considerado un servicio «a los altos intereses de la Patria». ${ }^{91}$ La disciplina y la política de incentivos se convirtieron en dos herramientas esenciales para evitar los conflictos. Un decreto de 27 de mayo de 1955 establecía que las nuevas empresas debían colaborar con los organismos correspondientes para proporcionar o facilitar el acceso a la vivienda de sus empleados y destinar un $10 \%$ de su capital inicial a esta cuestión. Desde su creación, SEAT construyó 1700 viviendas en veinte años, destinadas a sus trabajadores en régimen de alquiler o propiedad, para lo que la empresa concedía préstamos subvencionados. El conocido como «barrio SEAT», ubicado en la periferia de Barcelona, estaba dotado de servicios de ambulatorio, instalaciones deportivas, centro comercial y cooperativas de consumo para obreros y empleados. Conforme la mujer se fue incorporando también a la factoría, ofrecía guarderías, pero también subvencionaba los estudios de los hijos de los trabajadores. El objetivo era el de promover un sentimiento de orgullo en los trabajadores, mediante su pertenencia a la «familia SEAT» y su identificación con una marca de prestigio en la que, además, los salarios eran más altos y los trabajadores disponían de comedores propios. En el fondo, SEAT practicó una política cercana al modelo totalitario del fordismo ${ }^{92}$ pues no se limitó a regular solo la producción, sino también la vida privada de sus empleados.

Este sistema no fue óbice para el surgimiento de protestas de diversa naturaleza, que comenzaron de forma temprana en 1958, cuando un grupo de trabajadores participó en una manifestación ciudadana en apoyo a los mineros asturianos. La acción conllevó el cierre de la fábrica barcelonesa durante quince días y la aplicación de despidos y pérdida de antigüedad a los obreros implicados. Influenciados por el conflicto de la minería asturiana, las protestas se reprodujeron en 1963, cuando la formación clandestina Oposición Sindical Obrera realizó un llamamiento a la huelga de los trabajadores de SEAT por un auténtico sindicato y por los derechos de huelga y reunión. Las apelaciones tenían cada vez más calado entre una plantilla rejuvenecida, en la que las nuevas generaciones manifestaban mayor receptividad a las demandas de los sindicatos clandestinos.

91 Art. 6 del Reglamento de Régimen Interno de SEAT, 1962. Cit. en Sanz, 2017, p. 199. Véase también Tappi, 2010, p. 84.

92 Tappi, 2006 y 2010 , p. 88. 
La complicación de la conflictividad tuvo como respuesta el endurecimiento general de la política represiva del Gobierno. En el caso de SEAT, el conflicto se vio alimentado por los efectos provocados por la devaluación monetaria y la congelación salarial de 1967, que provocaría una reducción de la demanda de vehículos. A esto se añadiría el incremento del precio de los productos siderúrgicos en 1969, que afectó a todo el sector. La dirección de SEAT optó por no reducir la producción ni aumentar sus precios, con el fin de no desincentivar la demanda, pero las presiones para aumentar la productividad fueron respondidas con nuevos actos de protesta. En 1968, la dirección de la empresa, sin previa notificación a los órganos sindicales, decidió aumentar la producción del modelo 850 de 240 unidades a 500 en un solo turno. ${ }^{33}$ La decisión, en un contexto de congelación salarial y de suspensión de la negociación colectiva, provocó una serie de huelgas intermitentes que se saldaron con el despido de trescientos trabajadores, si bien, la mayoría fueron readmitidos posteriormente. En 1971, otra huelga finalizaría con la entrada de la policía en las instalaciones de la Zona Franca y la muerte de un trabajador. La reacción fue una huelga de quince días no solo en Barcelona, sino también en Madrid y Valencia. Las pérdidas fueron cuantiosas para la empresa: 2.600 millones de pesetas y la bajada de la producción en 18.000 vehículos. ${ }^{94}$ Por entonces, SEAT ya contaba con una plantilla de 26.000 trabajadores, ${ }^{95}$ que la situaban como una de las empresas nacionales más importantes, lo que aumentaba la repercusión de sus conflictos.

\section{Conclusiones}

Convertido en un icono de los cambios económicos, sociales y culturales de los años sesenta en España, el Seiscientos apareció en un momento que favoreció su expansión, debido al incremento paulatino del nivel de vida de los españoles y al surgimiento de una sociedad de consumo que hizo de la posesión de un vehículo un símbolo de status social, de progreso y de modernidad. El Seiscientos materializó el deseo de bienestar de una España que salía de las penurias económicas de la posguerra y se embarcaba en un proceso de desarrollo que retroalimentó los cambios

\footnotetext{
93 Tappi, 2010, p. 133

$94 A B C, 19$ de enero de 1972 , p. 21

95 Solé, 2001, p. 72
} 
sociales y culturales de una sociedad en transformación, tanto por la propia evolución del régimen franquista como por los acontecimientos que se estaban produciendo a nivel internacional, que llevaron a las democracias occidentales a replantear las reglas del juego para atender las demandas sindicales, políticas y sociales.

Sometida a un sistema político dictatorial, la sociedad española experimentó su propia transformación que, pese a incidir en un cambio de mentalidad, no se tradujo en una demanda masiva de democracia. La Historia ha demostrado que, a pesar de las corrientes reivindicativas de mayores derechos y libertades, capitaneadas por estudiantes, obreros, nacionalistas y sectores liberales de la Iglesia, la sociedad española se conformaba en su mayor parte con disponer de cierto bienestar económico, satisfecho por un incremento de su poder adquisitivo que le permitía el acceso a elementos de consumo anteriormente inalcanzables. La proliferación de los electrodomésticos, que facilitó la vida cotidiana de los españoles pero, sobre todo, la posibilidad de disponer de un automóvil, colmó las aspiraciones sociales de una mayoría, aunque la materialización de este deseo implicase un innegable sacrificio económico a nivel familiar. La extensión del aumento de poder adquisitivo a la mayoría de las capas sociales y la aparición de un mercado de segunda mano hizo que el Seiscientos lograse estar al alcance de los sectores más modestos.

La difusión del Seiscientos inauguró también un lenguaje popular, en el que la simplicidad tecnológica del utilitario promovería la creación de la ingeniosa denominación de «seatón», además de los múltiples nombres con los que fue conocido por su pequeño tamaño.

Pero el Seiscientos simbolizó mucho más: supuso la posibilidad de viajar y de ampliar la esfera geográfica de conocimiento, implicó la interconexión entre cultura rural y urbana y el contacto con culturas extranjeras diferentes; transformó el concepto de espacio urbano, en el que el individuo comenzaba a conquistar el espacio público concebido para una colectividad, y replanteó la estructura y el diseño urbano para amoldarlo a las exigencias de un nuevo fenómeno, surgido por la proliferación del uso del vehículo y que convirtió al tráfico en uno de los problemas en las grandes ciudades.

El Seiscientos inició también una tímida revolución en el ámbito femenino, al permitir a la mujer la conquista de pequeñas cuotas de libertad al frente de un volante y haciéndola partícipe de la ola de modernidad. También cambió los hábitos de sociabilidad de muchos jóvenes, que comenzaron a utilizar el Seiscientos familiar para ir a la universidad, lo con- 
virtieron en un elemento de status y diferenciación y ampliaron su núcleo geográfico de diversión.

Por su parte, SEAT no solo logró crear una imagen de marca, basada en el carácter nacional de la empresa, sino que también desarrolló una estrategia publicitaria acorde a los cambios que el uso del Seiscientos estaba generando en la sociedad. En este sentido, su diseño de marketing fue acertado, ya que estuvo dirigido a atraerse a los diferentes perfiles de consumidor, desde el padre de familia hasta la esposa y los jóvenes, conforme el Seiscientos extendía su uso a estos otros miembros de la familia. La evolución de sus lemas publicitarios muestra, no solo el cambio de este perfil de consumidores, sino también su carácter propagandístico, en el que trataba de conciliar los intereses de las diferentes familias políticas del régimen, a través de mensajes con apelativos a su carácter nacional, basados quizá en una cierta resistencia del régimen a perder un reducto autárquico. Progresivamente, los anuncios perdieron estos matices propagandísticos para centrarse en objetivos netamente comerciales, basados en un mayor pragmatismo y en el cambio de preferencias en el consumo de este vehículo.

Interesada también en la venta de sus nuevos modelos, SEAT decidió el cese de la producción del Seiscientos en pleno apogeo del vehículo, lo que incrementó su valor. A la altura de 1973, el Seiscientos estaba presente en todo el paisaje nacional y su uso se prolongó durante casi una década más.

El abandono de su producción coincidió, curiosamente, con la crisis del petróleo, que estallaría ese mismo año. Si el esplendor del Seiscientos simbolizó el periodo del desarrollismo, su final representó el gran declive económico que marcó la década de los setenta y comienzos de los ochenta. Su capacidad simbólica le debe mucho a los azares de su ciclo histórico, que se inició en vísperas del Plan de Estabilización y terminó cuando estaba a punto de producirse la crisis de los setenta, desencadenada, precisamente, por una subida exponencial del combustible.

SEAT representó también la lucha sindical de los sesenta, pues fue precisamente su carácter «nacional» lo que la convirtió en objeto de infiltración de los sindicatos clandestinos, que cada vez tenían un mayor ascendiente entre las nuevas generaciones de jóvenes trabajadores que se integraron en sus fábricas. Pese a la política de control de la empresa sobre sus empleados y los incentivos, como forma de desactivar cualquier reivindicación, SEAT finalizó el periodo de los sesenta con un aumento de la conflictividad laboral que presionó a la dirección hacia la realiza- 
ción de un conjunto de reformas tendentes a aumentar la representatividad de los trabajadores, si bien, al igual que en el resto de las empresas públicas y privadas, estos cambios se hicieron en el marco de la estructura sindical marcada por el régimen, lo que no satisfizo a muchos trabajadores. Las movilizaciones, sin embargo, no dejaron de estar circunscritas a la petición de mejoras laborales, pero dentro del clima general, contribuyeron a dificultar la situación para un régimen político cuya respuesta fue el aumento de la represión ante la incapacidad de controlar un panorama cada vez más complejo. De este modo, si el Seiscientos simbolizó el desarrollismo franquista, su empresa matriz, SEAT, fue un símbolo del nuevo sindicalismo antifranquista.

En la actualidad, el Seiscientos se ha convertido en un objeto fetiche para coleccionistas impulsados, bien por la nostalgia, bien por el propio simbolismo de este vehículo. Decenas de clubes de amigos del Seiscientos organizan encuentros y participan en redes sociales, manteniendo viva la memoria de este coche y alimentando su mito. Estos clubes se han convertido en los depositarios del recuerdo que muchos españoles guardan del lado amable del desarrollismo, una etapa a veces idealizada como «aquellos maravillosos años», en los que el Seiscientos representó un extraño consenso social a la vez de adhesión y lucha contra el franquismo.

\section{Bibliografía}

Alted, Alicia y Aubert et al., Paul, 'Triunfo' en su época, Madrid, Casa de Velázquez, 1995.

André-Bazzana, Bénédicte, Mitos y mentiras de la Transición, Barcelona, El Viejo Topo, 2006.

Anuario Estadístico de Accidentes de Circulación, Dirección General de Tráfico, Ministerio de Gobernación. Años 1961 a 1973.

BALFOUR, Sebastian et al., Barcelona malgrat el franquisme: la SEAT, la ciutat $i$ la represa sense democràcia, Sebastian Balfour (ed.), Ajuntament de Barcelona, 2012.

BARrera, Carlos, El diario 'Madrid'. Realidad y símbolo de una época, Pamplona, EUNSA, 1995.

CAlabrese, Omar, «Il loughi della memoria. Simboli e mitti dell'Italia unita», en L'utilitaria, Bari, Laterza, 1996.

Cañellas Mas, Antonio, «La tecnocracia franquista: el sentido ideológico del desarrollo económico», en Studia Historica Contemporánea, n. ${ }^{\circ}$ 24, 2006, pp. 257-288. 
CARr, Raymond y Fusi, Juan Pablo, España de la dictadura a la democracia, Barcelona, Planeta, 1979.

CASANOVA, Julián, «Modernización y democratización: reflexiones sobre la transición española a la democracia», en Modernización, desarrollo político y cambio social, Carneto Abat (ed.), Madrid, Alianza Universidad, 1992.

CASSANY, Lluís y LóPEZ, Isabel, El SEAT 600: símbolo de una época, Madrid, Susaeta Ediciones, 1996.

CAtalan, Jordi, «La creación de la ventaja comparativa en la industria automovilística española, 1898-1996», en Revista de Historia Industrial, N. ${ }^{18}$, 2000, pp. 113-155.

Catalan, Jordi, «La SEAT del Desarrollo, 1948-1972», en Revista de Historia Industrial, N. $.30,2006.1$, pp. 143-192.

DE LA TORRE, Joseba, «España como mercado: oportunidades de negocio, desarrollo económico y franquismo», en HISPANIA. Revista Española de Historia, N. ${ }^{\circ} 237,2011$, vol. LXXI, pp. 181-206.

Eslava GalÁn, Juan, De la alpargata al seiscientos, Barcelona, Planeta, 2010.

Feliú, José, Atlas ilustrado del SEAT 600, Madrid, Susaeta, 2007.

FERnÁNDEZ DE LA MoRA, Gonzalo, El crepúsculo de las ideologías, Madrid, Espasa Calpe, 1965.

FERNÁNDEZ NAVARRETE, Donato, «La política económica exterior del franquismo: del aislamiento a la apertura», en Historia Contemporánea, N. ${ }^{\circ}$ 30, 2005, pp. 49-78.

FuENTES ARAgONÉS, Juan Francisco, Luis Araquistáin y el socialismo español en el exilio, Madrid, Biblioteca Nueva, 2002.

FuENTES QUINTANA, Enrique, «El modelo de economía abierta y el modelo castizo en el desarrollo económico de la España de los 90», en Anales de la Real Academia de las Ciencias Morales y Políticas, 1995, n. ${ }^{\text {7 } 72, ~ p p . ~ 255-~}$ 332.

Fusi, Juan Pablo et al., Franquismo. El juicio de la Historia, José Luis García Delgado (Coord.), Madrid, Temas de Hoy, 2005.

Fusi, Juan Pablo y PALAFOX, Jordi, España 1808 - 1988. El desafío de la modernidad, Madrid, Espasa Calpe, 1997.

Fusi, Juan Pablo, «La reaparición de la conflictividad en la España de los sesenta», en J. Fontana, (ed.), España bajo el franquismo, Barcelona, Crítica, 1986.

García RuIz, José L., Sobre ruedas: una historia crítica de la industria del automóvil en España, Madrid, Síntesis, 2003.

Geli, Carles y Huertas Clavería, J.M., Las tres vidas de 'Destino', Barcelona, Anagrama, 1991.

Gimeno Valledor, Pablo, El SEAT 600 ... y España ya no fue la misma, Madrid, CIE Inversiones Editoriales Dossat, 2000. 
GómEZ BENITO, Cristóbal, «Una revisión y una reflexión sobre la política de colonización agraria en la España de Franco», en Historia del Presente, N. ${ }^{\circ} 3$, 2004, pp. 65-86.

GonzÁLEZ, Carmen y OrTIZ, Manuel, «Control social y control policial en la dictadura franquista», en Historia del Presente, N. ${ }^{\circ}$ 9, 2007, pp. 27-47.

GonzÁlez Cuevas, Pedro Carlos, «La derecha tecnocrática», en Historia y Política, N. ${ }^{\circ} 18,2007$, pp. 23-48.

GoÑ Apesteguía, Carlos, Teoría de la razón política. El pensamiento político de Gonzalo Fernández de la Mora, Tesis doctoral, Universidad de Navarra, 2011.

HoBSBAwm, Eric, Historia del siglo XX, Barcelona, Crítica, 2006.

LAFUENTE SOLER, Myriam, La ideología del diario 'Madrid': historia del cierre de un periódico en la época franquista, Murcia, Universidad Católica de San Antonio, 2002.

Miguélez Lobo, Faustino, SEAT, la empresa modelo del régimen, Barcelona, Dopesa, 1977.

Molinero, Carme e Ysàs, Pere, Productores disciplinados y minorías subversivas, Madrid, Siglo XXI, 1998.

MONTERO, Feliciano, «Las derechas españolas y el catolicismo español: del integrismo al socialcristianismo», en Historia y Política, N. ${ }^{\circ} 18,2007$, pp. 101128.

Morán, Gregorio, Miseria, grandeza y agonía del Partido Comunista de España (1939-1985), Madrid, Akal, 2017.

Otaola GonzÁlez, Paloma, «La música en la España franquista: rock, ye-ye y beat en la primera mitad de los años 60», en ILCEA. Revue de l'Institut des langes et cultures d'Europe, Amérique, Afrique, Asie at Australie, (En línea), 16, 2012. Publicado el 4 de julio de 2012. https://journals.openedition. org/ilcea/1421

Preston, Paul, España en crisis: la evolución y decadencia del régimen de Franco, Madrid, FCE, 1978.

PuIG, Nuria y Álvaro, Adoración, «Estados Unidos y la modernización de los empresarios españoles, 1950 - 1975: un estudio preliminar», en Historia del Presente, N. ${ }^{\circ}$ 1, 2002, pp. 8-29.

REIG CRUAÑES, José, Identificación y alienación. La cultura política y el tardofranquismo, Publicacions de la Universitat de València, 2007, pp. 197-205.

Roca MASEDA, Ramón, Nuestro SEAT, Gerona, Benzina, 2006.

SAN ROMÁN, Elena, «El nacimiento de SEAT: autoarquía e intervención del INI», en Revista de Historia Industrial, n. ${ }^{\circ}$ 7, 1995, pp. 141-165.

SÁNCHEZ RECIO, Glicerio, «La percepción de los cambios en los años sesenta», en Studia Historica. Historia contemporánea, N. . 21, 2003, pp. 213-229.

SANZ NeIRA, José, Historia de SEAT, Barcelona, Arant, 2017.

SolÉ, Eulàlia, SEAT, 1950 - 1993, Barcelona, Ediciones de la Tempestad, 1994. 
SoLÉ, Eulàlia, SEAT 600: un coche de leyenda, Barcelona, Benzina, 2001.

TAMAMES GómEz, Ramón, «La modernización de la economía española (19292004)», en ICE 75 años de política económica española, N. ${ }^{\circ}$ 826, Noviembre 2005.

TAPPI, Andrea, «El fordismo en la industria europea del automóvil y la SEAT (1950-1970)», en Revista de Historia Industrial, N. . 34, 2007. 2, pp. 97-128.

TAPPI, Andrea, SEAT, modelo para armar: fordismo y franquismo (1950-1980), Valencia, Germania, 2010.

Tortella, Gabriel, El desarrollo de la España contemporánea. Historia económica de los siglos XIX y XX, Madrid, Alianza, 1994.

TOWSON, Nigel et al., España en cambio. El segundo franquismo (1959-1975), Nigel Towson (Ed.), Madrid, Siglo XXI, 2007.

VALLEJo Pousada, Rafael, «Turismo y desarrollo económico en España durante el franquismo, 1939-1975», en Revista de la Historia de la Economía y de la Empresa, VII, 2013, pp. 423-462.

VÁzQuez Montalbán, Manuel, Crónica sentimental de España, Barcelona, Random House Mondadori, 2003.

\section{Fuentes hemerográficas}

$A B C$

La Codorniz

Destino

¡Hola!

Hogar y Pueblo

Madrid

Marca

La Nueva España

Proa

Triunfo

La Vanguardia

\section{Webgrafía}

https://diariomadrid.net/index.php https://elpais.com/economia/2007/06/27/actualidad/1182929574_850215.html http://www.elmundo.es/motor/MVnumeros/97/MV006/MV006mingote.html http://www.ine.es

http://www.rtve.es/filmoteca/no-do/not-1476/1487620/ 
http://www.rtve.es/alacarta/videos/documentales-b-n/coche-para-todos/2845434/ http://www.rtve.es/alacarta/videos/informe-semanal/fue-informe-ultimo-seat600-1973/2047728/

http://www.rtve.es/alacarta/videos/informe-semanal/informe-semanal-60-del$600 / 4048960 /$

http://www.seat.es/somos-seat/seat-600.html

https://www.youtube.com/watch?v=ad8jy8IyyxQ

https://www.youtube.com/watch?v=p_PSvAeQDOM

https://www .youtube.com/watch?v=BnoraqbFEqs

https://www.youtube.com/watch?v=JANFJgG_qDM

\section{Financiación y Agradecimientos}

Resultado del Proyecto de Investigación «Diccionario de símbolos políticos y sociales: claves iconográficas, lugares de memoria e hitos simbólicos en el imaginario español del siglo XX», del Ministerio de Ciencia, Innovación y Universidades (Ref. HAR2016-77416-P).

Mi agradecimiento a Juan Francisco Fuentes Aragonés, José Carlos Rueda Laffond y Agustín Martínez de las Heras por la información que me han facilitado para la elaboración de este artículo.

\section{Datos de la autora}

Isabel Martín Sánchez es profesora de la Facultad de Ciencias de la Información de la Universidad Complutense de Madrid. Sus líneas de investigación se han centrado en la Historia del Periodismo y de la propaganda y la representación de la Historia a través de los medios de comunicación. Directora del Proyecto titulado Televisión y Memoria. Estrategias de representación de la Guerra Civil y la Transición, ha participado como investigadora en varios proyectos competitivos centrados en los derechos humanos y la democracia, en las narrativas mediáticas de la Historia, la memoria y la posmemoria y en la representación de los símbolos políticos y sociales. 